Robert J. Byrick MD, *

J. Brendan Mullen MD, $†$

Patricia M. Murphy MD, $\ddagger$

J. Colin Kay, ${ }^{*}$

Thomas E. Stewart MD, $\uparrow$

Gerald Edelist MD‡

\title{
Inhaled nitric oxide does not alter pulmonary or cardiac effects of fat embolism in dogs after cemented arthroplasty
}

Purpose: We examined the effect of inhaled nitric oxide $(\mathrm{NO})$ on the acute pulmonary hypertension and right ventricular (RV) dilation after fat embolism.

Methods: $A$ bilateral cemented arthroplasty ( $B C A)$, created fat embolism in 20 dogs. In Part $A, 12$ dogs were randomized to an NO group ( $n=6$, inhaled NO 40 ppm before BCA and throughout the study) or a control group ( $n=6)$. In Part $B$, a third group of dogs $(n=8)$ were given NO $20-40$ ppm 2-3 min after BCA when pulmonary artery pressure (PAP) increased. Transesophageal echocardiography (TEE) and invasive hemodynamic monitoring evaluated the hemodynamic response to BCA. Postmortem, quantitative morphometry was used to estimate the number of fat emboli and diameter of lung vessel occluded by fat.

Results: Part A: The increase in PAP in the NO group ( $16 \pm 1$ to $34 \pm 9 \mathrm{mmHg}$ ) within three minutes of BCA was not different from that in the control group ( $14 \pm 4$ to $35 \pm 9 \mathrm{mmHg}$ ). Within three minutes of $B C A$, TEE demonstrated RV dilation in all groups $(P<0.05)$ but there was no difference in the change in $\mathrm{RV}$ area in the NO and control groups. When NO was given after BCA, no difference in PAP or RV dilation was noted from that in the control group. There were no differences, at post mortem, between the groups in the diameter of lung vessel occluded by fat Conclusion: Whether given before the embolic insult or two to three minutes after the onset of pulmonary hypertension, inhaled NO did not attenuate the acute pulmonary hypertension or RV dilation after cemented arthroplasty.

Objectif : Étudier l'effet de l'oxyde nitrique inhalé (NO) sur l'hypertension pulmonaire aiguë et la dilatation du ventricule droit (ND) après une embolie graisseuse.

Méthode : Une arthroplastie bilatérale cimentée $(A B C)$ a créé une embolie graisseuse chez 20 chiens. Dans la partie A de l'essai, 12 chiens ont été répartis de façon aléatoire vers un groupe $N O(n=6,40 \mathrm{ppm}$ de NO inhalé avant l'ABC et tout au long de l'étude) ou vers un groupe témoin $(n=6)$. Dans la partie $B$, un troisième groupe de chiens $(n=8)$ ont reçu 20-40 ppm de NO, 2-3 min après l'ABC, au moment où la pression de l'artère pulmonaire (PAP) s'est élevée. On a évalué la réponse hémodynamique à l'ABC par échocardiographie transcesophagienne (ETO) et par monitorage hémodynamique effractif. Après la mort, on a utilisé la morphométrie quantitative pour évaluer la proportion du système vasculaire pulmonaire obstruée par la graisse.

Résultats : Partie A : Laugmentation de PAP dans le groupe $\mathrm{NO}(16 \pm \mathrm{I}$ à $34 \pm 9 \mathrm{mmHg})$, en moins de trois minutes suivant l'ABC, était semblable à celle du groupe témoin $(14 \pm 4$ à $35 \pm 9 \mathrm{mmHg})$. Moins de trois minutes après I'ABC, l'ETO a montré une dilatation du VD dans tous les groupes $(P<0,05)$ mais pas de différence intergroupe de changements survenus au VD. Aucune différence de PAP ou de dilatation du VD, en comparaison avec les chiens témoins, n'a été notée suivant l'administration de NO. À l'autopsie, il n'y avait pas de différence intergroupe quant au diamètre du vaisseau pulmonaire obstrué par la graisse.

Conclusion : Que le NO soit administré avant l'embolie ou deux ou trois minutes après le début de l'hypertension, il ne réduit pas l'hypertension pulmonaire aiguë ou la dilatation du VD à la suite d'une arthroplastie cimentée.

From the Departments of Anaesthesia, St. Michacl's Hospital* and Sunnybrook Health Sciences Centre, $\ddagger$ Department of Pathology and Laboratory Medicine, Mr. Sinai Hospital, University of Toronto. $\dagger$

Address correspondence to: Dr. Robert Byrick, Department of Anaesthesia, St. Michael's Hospital, 30 Bond Street, Toronto, Ontario, Canada M5B 1W8. Phone: 416-864-5892; Fax: 416-864-6014.

This study was supported by a grant from the Ontario Thoracic Society.

Accepted for publication March 17, 1999. 


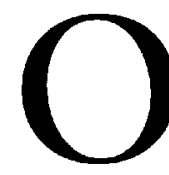

RTHOPEDIC procedures which result in pressurization of the medullary cavities of long bones are associated with embolization of marrow contents. ${ }^{1-3}$ Clinical studies, using transesophageal echocardiography (TEE) have shown that many patients experience emboli at the time of cement and prosthesis insertion and also during medullary rod fixation of fractured femurs. ${ }^{1,3-5}$ Occasionally, a patient with reduced cardiopulmonary reserve, may experience sudden cardiac arrest or a severe hypotensive crisis associated with massive fat and marrow embolism. ${ }^{6}$

Using a bilateral cemented arthroplasty (BCA) procedure in anesthetized dogs, we have simulated the cardiopulmonary response to acute fat and marrow embolism. ${ }^{7}$ This response is characterized by a sudden increase in pulmonary artery pressure (PAP) and pulmonary vascular resistance (PVR) with a decrease in stroke volume (SV) and arterial partial pressure of oxygen $\left(\mathrm{PaO}_{2}\right) .^{7}$ We have also shown that embolized fat moves through the lung vasculature into the systemic circulation within minutes of BCA. ${ }^{8}$ The decrease in stroke volume and cardiac output occurs within seconds and is associated with acute right ventricular (RV) dilation. ${ }^{7}$ Since cardiac arrest after cement and prosthesis insertion appears to be secondary to pulmonary hypertension with RV dilation, any therapeutic intervention that minimizes the increase in PAP may also reduce cardiopulmonary instability.

Inhaled nitric oxide (NO) is a selective pulmonary vasodilator that reduces elevated PAP and PVR in patients with acute lung injury. ${ }^{9}$ By selectively vasodilating ventilated areas of the lung, inhaled NO can improve matching of perfusion to ventilation and oxygenation. ${ }^{10}$ This investigation was designed to assess whether inhaled NO may prevent or ameliorate the acute pulmonary hypertension and secondary decrease in SV associated with RV dilation which occurs within minutes of BCA in an animal model. We also studied the effect of inhaled NO on the distribution of the diameter of vessels occluded by fat emboli. The rationale for studying the histology was to assess the effect of NO-induced vasodilatation on the rate of dispersion of fat emboli within the lung vasculature.

\section{Methods and materials}

This study was approved by the local animal care committee. All dogs were treated in accordance with the regulations of the Canadian Council on Animal Care.

i) Anesthesia and cannulation: Twenty mongrel dogs weighing $29.9 \pm 4.6 \mathrm{~kg}$ were anesthetized with 30 $\mathrm{mg} \cdot \mathrm{kg}^{-1}$ sodium pentobarbital $i v$. After tracheal intubation, anesthesia was maintained with isoflurane $(1 \%)$ in air supplemented with oxygen to maintain an inspired oxygen concentration of $26-31 \%$. The lungs were ventilated by positive pressure (VC20-1, Airshields Inc., Hatboro, Pennsylvania) via a circle anesthesia breathing circuit with a carbon dioxide $\left(\mathrm{CO}_{2}\right)$ absorber. Ventilation was adjusted to maintain an arterial partial pressure of carbon dioxide $\left(\mathrm{PaCO}_{2}\right)$ between 35 and 40 $\mathrm{mmHg}$. We infused $10 \mathrm{ml} \cdot \mathrm{kg} \cdot \mathrm{hr}^{-1}$ normal saline throughout the experiment. Pancuronium bromide, $0.15 \mathrm{mg} \cdot \mathrm{kg}^{-1}$, ip was given prior to surgery and intermittent doses of $250 \mu \mathrm{g}$ fentanyl citrate $i p$ were given as required to maintain a heart rate $<120 \mathrm{bpm}$ prior to cemented arthroplasty.

An arterial cannula (14 gauge) was inserted into the right femoral artery for blood sampling. A $7 \mathrm{~F}$ triplelumen balloon-tipped pulmonary artery catheter was inserted into the left external jugular vein and advanced into the pulmonary artery to measure pulmonary artery pressure (PAP), pulmonary artery occluded pressure (PAOP) and right atrial pressure (RAP). A MIKROTIP7 catheter pressure transducer (Millar@ Instruments, Houston, Texas) was inserted into the left carotid artery to monitor aortic blood pressure (BP).

ii) Nitric Oxide Administration and Analysis. To permit the administration of inhaled NO at a pre-determined point in the experimental protocol the anesthetic breathing circuit was modified as follows. Nitric Oxide was delivered from a K size tank (486 ppm NO with a $\mathrm{N}_{2}$ balance). The NO was mixed with nitrogen gas using a Bird oxygen blender, thereby controlling the NO concentration entering the breathing circuit. The $\mathrm{N}_{2} / \mathrm{NO}$ gas flow rate was controlled using a flowmeter (Cole Parmer, Chicago, IIl) and entered the circle anesthesia breathing circuit in the inspiratory limb $200 \mathrm{~cm}$ upstream from the endotracheal tube. The $\mathrm{N}_{2} / \mathrm{NO}$ gas mixed with the oxygen supplemented air to constitute the inspired gas mixture. The administered NO concentration was measured $150 \mathrm{~cm}$ downstream from the entry point using a chemiluminescence NO analyzer (CLD 700 AL Med; ECO Physics, $\mathrm{CH}$ 8635, Durnten, Switzerland). An averaging time of seven seconds was allowed for each measurement and a lower detection limit of $0.5 \mathrm{ppb}$ with a precision of \pm $0.5 \mathrm{ppb}$ has been reported. ${ }^{11}$ The administered concentration of NO was controlled by varying the blend of $\mathrm{N}_{2} / \mathrm{NO}$ through the flowmeter.

The inspired oxygen concentration was continuously monitored using an Ohmeda $5120 \mathrm{O}_{2}$ monitor located directly adjacent to the endotracheal tube, 170 $\mathrm{cm}$ downstream from the entry point of the $\mathrm{N}_{2} / \mathrm{NO}$ gas mixture. The NO analyzer was calibrated for each experiment using the one point calibration technique described in the user manual (section 6.2.3; pg 48- 
49). The linearity of this NO analyzer had been previously determined. 11

iii) Transesophageal Echocardiography: TEE was performed using a $5.0 \mathrm{MHZ}$ Biplane probe (model 21363A Hewlett-Packard Co., Andover, Mass.). Under general anesthesia, the TEE probe was inserted into the esophagus and advanced a distance of 32 $\mathrm{cm}$ from the incisors. At this position, a complete examination of cardiac structure and function was performed to ensure that there were no intra-cardiac lesions. Specifically, all animals were examined using colour flow Doppler analysis to exclude the presence of a patent foramen ovale (PFO). The absence of a PFO was confirmed at postmortem examination.

The TEE probe was then advanced into the stomach to a level of $60 \mathrm{~cm}$ from the incisors to produce a transgastric short axis view of the right and left ventricles at the level of the mitral valve. The mitral valve level was chosen as it, unlike the mid-papillary muscle level, could be consistently reproduced to allow estimation of the function and size of the ventricles. ${ }^{7}$ This was technically difficult and required extreme anterior and rightward flexion of the scope. This view provided the optimal position to observe the contractility of both ventricles, assess ventricular areas and grade the venous embolic load.

The TEE images were assessed by two independent echocardiographers who were unaware of whether NO had been administered and did not know the hemodynamic response of the dog or post mortem pathology. The physiological effect of the embolic load on cardiac size was assessed using $\mathrm{RV}$ areas which were calculated from cavitary measurements at the level of the mitral valve at end-diastole (Sonos 1000 On-Line Analysis, Hewlett-Packard Co., Andover, Massachusetts). Both echocardiographers independently examined the tapes and analyzed the same representative frame at each measurement period. The endocardial border was traced manually and the state of RV dilation was determined as the largest area at end-diastole. When there was a discrepancy of $>10 \%$ in right ventricular dimensions, the tape was reviewed and a consensus reached.

iv) Surgical technique: A bilateral cemented arthroplasty (BCA) was performed by exposing both distal femoral condyles using a transverse skin incision and division of the patellar tendons. The distal femoral canal was entered by drilling through the patellofemoral groove and reaming to a depth of approximately $10 \mathrm{~cm}$ using successively larger reamers up to $9 \mathrm{~mm}$ diameter. The medullary canal was filled with normal saline and low viscosity bone cement (Surgical Simplex P, Howmedica International Ltd.,
London, England). The bone cement was injected simultaneously under manual pressure into both medullary canals. When the cavities were filled, a solid, contoured metal rod was hammered into each medullary cavity to simulate prosthesis insertion.

v) Experimental Protocol: A BCA procedure was performed on all dogs $(n=20)$. Right ventricular area was monitored by TEE continuously throughout the surgical procedure and recorded on videotape for later analysis. Heart rate (HR), BP, RAP and PAP were monitored continuously using a Gould ES 1000 recorder (Gould Inc., Cleveland, Ohio) and analog to digital conversion using an AT-Codas system interface card (Dataq instruments, Akron, $\mathrm{OH}$ ) at a rate of $250 \mathrm{~Hz}$ per channel on an IBM compatible 80386 computer.

Prior to reaming, hemodynamic measurements including PAOP were recorded on the computer. Three determinations of thermodilution cardiac output (Q) were measured and the mean together with the PAOP was used to calculate pulmonary vascular resistance (PVR) using standard equations. Ventricular areas were calculated and arterial blood gas measurements were performed. These measurements were repeated following reaming and at $3,5,15$ and 30 min following BCA. Post-reaming measurements were used as baseline values as they were made only minutes before $B C A$ and hence any changes related to intravascular volume depletion from surgery are minimized.

There were two phases of the investigation, Part A and Part B. In Part A, 12 dogs were randomly allocated to one of two groups to investigate the effect of inhaled nitric oxide given before cement and prostheses insertion. In the NO group ( $\mathrm{n}=6)$, NO (40 ppm) was added to the inspired gas using nitrogen as a carrier, prior to reaming of the medullary cavities. In the control group $(n=6)$ prior to reaming of the medullary cavities, nitrogen was added to the inspired gas, at approximately the same flow rate as the $\mathrm{N}_{2} / \mathrm{NO}$ gas mixture in the NO group. In this way $\mathrm{F}_{\mathrm{I}} \mathrm{O}_{2}$ was similar in the control and NO groups.

In Part $B$, a third group ( $n=8)$ was studied to assess whether the acute increase in PVR or the change in $\mathrm{PaO}_{2} / \mathrm{F}_{\mathrm{I}} \mathrm{O}_{2}$ ratio could be influenced by inhaled NO (20-40 ppm) when pulmonary hypertension was already present. Nitric oxide was added to the inspired gas 2-3 minutes after BCA, when both acute pulmonary hypertension and RV dilation were established, based on continuous hemodynamic and TEE recordings. Inhaled NO was added, first at a concentration of $20 \mathrm{ppm}$ and $15 \mathrm{~min}$ later, at $40 \mathrm{ppm}$.

vi) Morphometric analysis: At the end of the study all dogs were killed by an overdose of pentobarbital and injection of $\mathrm{KCl}$. A thoracotomy was performed 
TABLE I Hemodynamic data, before and after bilateral cemented arthroplasty, for the control group $(n=6)$ and the NO group ( $n=6)$ in which NO (40 ppm) was administered before BCA.

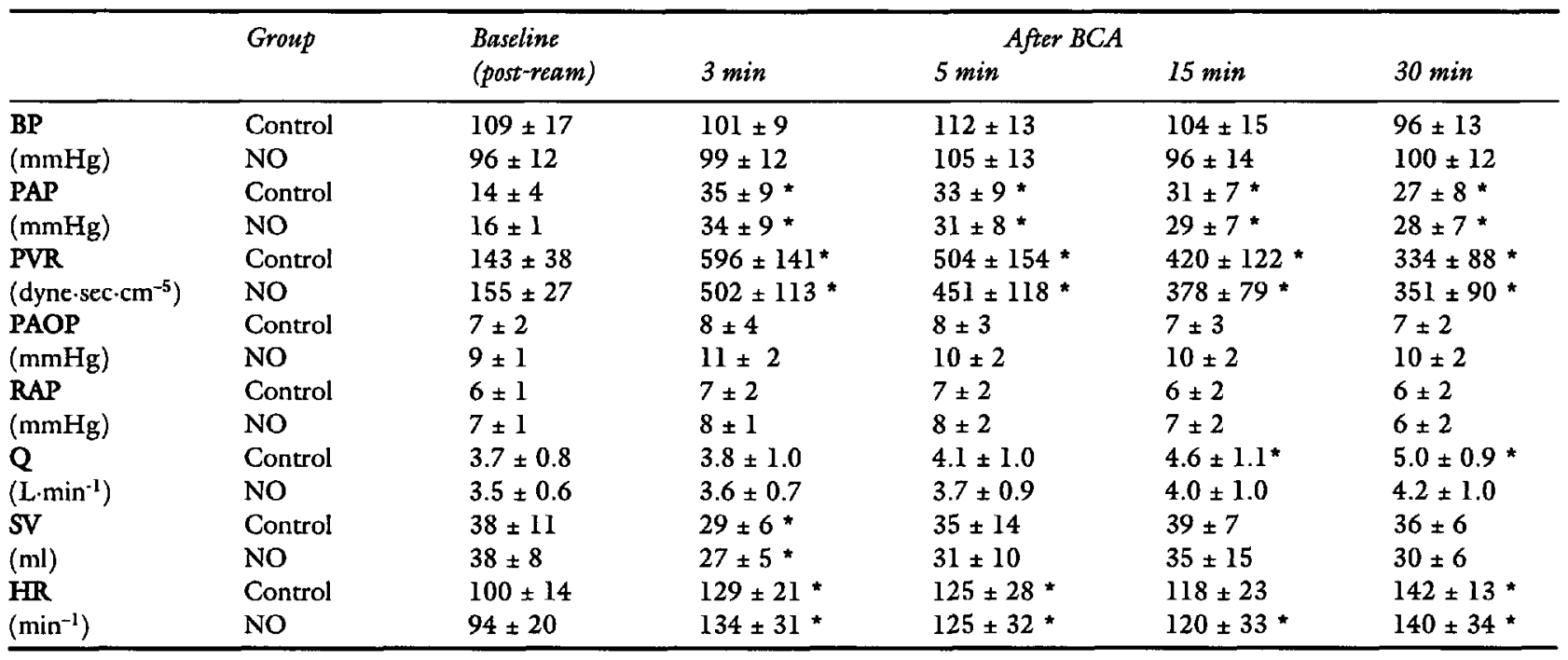

Values are mean $\pm S D$.

* denotes a significant difference from post-reaming baseline $P<0.05$.

There were no significant differences between the control and NO group.

and the pulmonary vessels ligated. The lungs were removed en bloc and fixed in inflation with neutral buffered formalin $10 \%$ at a pressure of $25 \mathrm{~cm}$ of fixative. After fixation for $72 \mathrm{hr}$, the lungs were sectioned in the mid-sagittal plane and three stratified random blocks of known size were taken from the mid-sagittal slice of each lung. These samples were post-fixed in Flemming's solution for $72 \mathrm{hr}$, washed in running water for $24 \mathrm{hr}$, then processed for histological examination and cut at $5 \mu \mathrm{m}$ thickness.

A coding system was used so the pathologist who performed the morphometric analysis was unaware of the physiologic changes or surgical technique used for each dog. The sections were evaluated using a TVbased image analysis system (BQ Meg IV, R and M Biometrics, Nashville TN) with a Leitz Dialux 22 microscope attached to a Sony CCD video camera connected to an AST 486 microcomputer. For each animal, 12 stratified random fields (each $1 \mathrm{~mm}^{2}$ ) from the six lung samples were examined for a total area of $72 \mathrm{~mm}^{2}$ per animal. The measurements were made at a final optical magnification of $245 x$. The grey-scale image was converted to a binary (black and white) image by manual selection of the threshold value which best delineated the emboli from background. The diameter was calculated for each embolus. The mean number of fat emboli and the diameter of vessel occluded by fat were calculated for each dog. vii) Statistical Analysis. Data are reported as the mean value \pm one standard deviation. Data were analyzed using the SAS@ (Statistical Analysis System) statistical package. We used the SAS general linear model two way analysis of variance procedure for repeated measures to analyze data from sequential measurements and a one way analysis of variance was used to assess differences between the number of emboli occluding vessels of specific diameters. When a significant F-ratio was present $(P<0.05)$ multiple comparisons between baseline (pre-cement) and other measurements were made using Dunnett's and Tukey's tests. A probability value $<0.05$ was considered significant.

\section{Results}

\section{Part A: Inbaled NO given before BCA}

Hemodynamic DaTA: There were no differences between the control group and the NO group in the mean weight of dogs studied or the grade of embolic event as detected by TEE. All dogs had opaque echogenic material visualized on TEE within seconds of BCA. Using Ereth's grading system (range 0-9) these opacities corresponded to a grade 7-9. 'The features used in this grading system include the amount of right atrium filled by echogenic particles, the duration of opacification and the appearance of large diameter echogenic particles. A grade 7-9 embolic load reflects a large amount of echogenic material. 


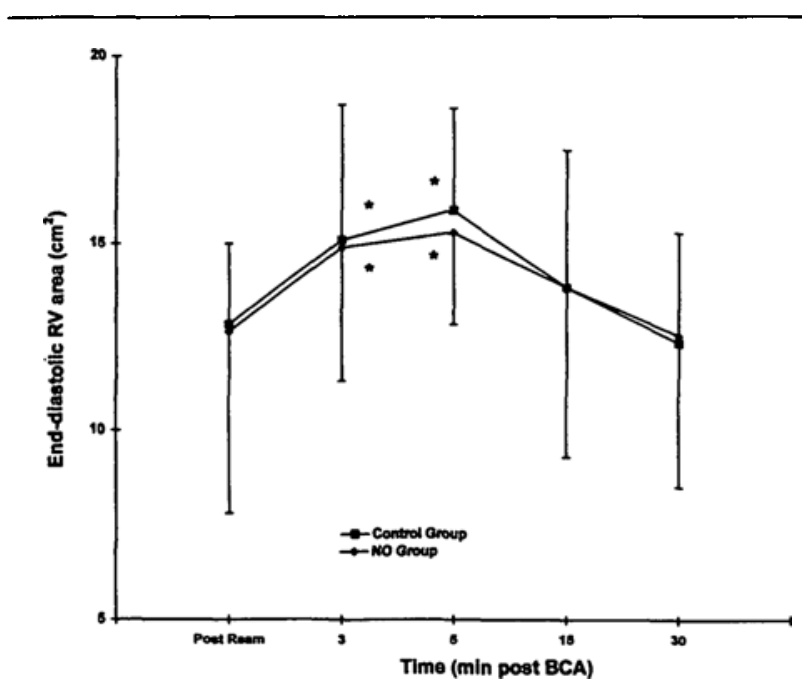

FIGURE 1 The end diastolic right ventricular (RV) area (mean \pm SD) measured by TEE at each measurement time. In both groups the post ream measurement is used as baseline. * indicates significantly different from post ream $P<0.05$.

Hemodynamic measurements at each time period are shown in Table I. There were no intergroup differences in the pre-reaming or post-reaming (baseline) values of PAP, PVR, BP, RAP, PAOP, cardiac output or SV. Compared with the post-ream (baseline) values, PAP and PVR increased after BCA in both groups at all time intervals. The increase in PAP and PVR from baseline (Table I) was not different between the groups. No changes in BP, PAOP or RAP were noted, however stroke volume decreased in all dogs within three minutes of $\mathrm{BCA}$ and returned to baseline within five minutes. Cardiac output was maintained in both groups in spite of the decreased SV. The maintenance of $\mathrm{CO}$ was the result of a marked increase in HR (Table I). No difference between the groups was noted in the increase in HR or decrease in SV.

Figure 1 shows the measured end-diastolic RV area (mean $\pm \mathrm{SD}$ ) for both groups at each measurement time. The RV area increased in both groups within three minutes. However, there was no significant difference in the amount of RV dilation when the NO group with an increase of $2.3 \pm 1.7 \mathrm{~cm}^{2}$ was compared with the control group $2.2 \pm 2.2 \mathrm{~cm}^{2}$. The $\mathrm{RV}$ area returned to baseline values by $15 \mathrm{~min}$ and no differences were noted between the end diastolic RV areas of the control and NO group at any time period.

GAS EXCHANGE DATA: Table II shows the measured $\mathrm{PaO}_{2}$ and $\mathrm{PaCO}_{2}$ at each time period as well as the $\mathrm{F}_{\mathrm{I}} \mathrm{O}_{2}$. A decrease from baseline $\mathrm{PaO}_{2}$ was found at

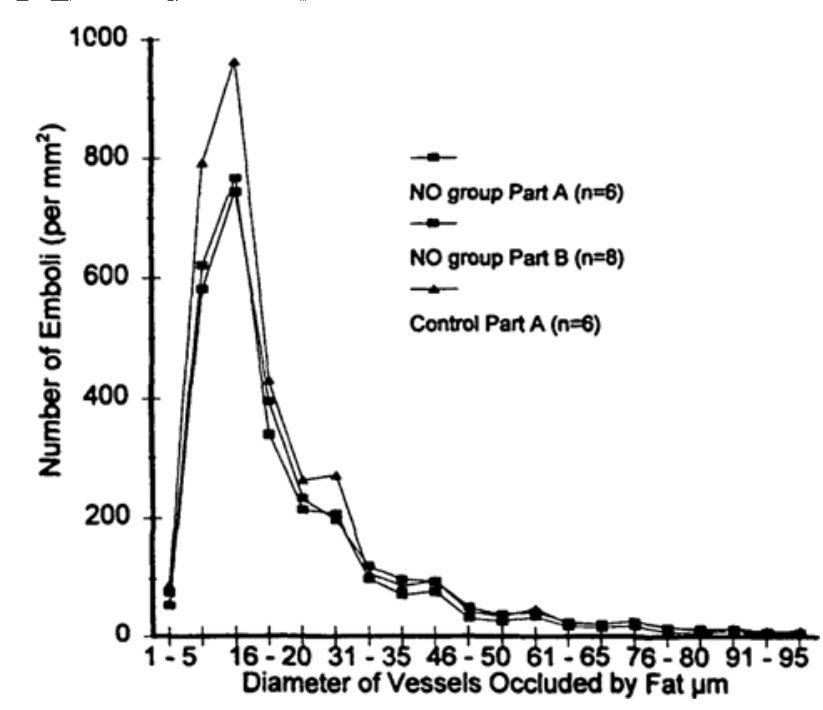

FIGURE 2 The mean number of pulmonary fat emboli of each diameter range are shown for each group. In Part $A$, inhaled $\mathrm{N}_{2}$ was given in the control group $(n=6)$ and inhaled NO was given in the NO group before BCA. In Part B, inhaled NO $20 \mathrm{ppm}$ was given $1-3$ minutes after $B C A$ and increased to $40 \mathrm{ppm} 15 \mathrm{~min}$ after BCA.

each time period in both groups. The $\mathrm{PaO}_{2} / \mathrm{F}_{\mathrm{I}} \mathrm{O}_{2}$ ratio decreased in both groups within three minutes of BCA and remained below baseline value throughout the study. No difference was noted between the control and $\mathrm{NO}$ groups. No change in $\mathrm{PaCO}_{2}$ was noted in either group.

\section{Part B: Addition of Inbaled NO after $B C A$}

In Part $\mathrm{B}, \mathrm{a} B C A$ was performed $(\mathrm{n}=8)$ as in the control group. The post-ream (baseline) measurements were not different in Part B when compared with the control or NO groups, however inhaled NO (20 ppm) was added 2-3 min after BCA when pulmonary hypertension and RV dilation were established. The PAP increased from baseline $(16 \pm 4 \mathrm{mmHg})$ to $33 \pm 8$ $\mathrm{mmHg}(P<0.001)$ at the one minute measurement and remained elevated throughout the $\mathbf{3 0}$ min study period. Table III summarizes the hemodynamic data from this group. The addition of inhaled NO did not cause a significant decrease in PAP at the three or five minute measurement (Table III) compared to the one minute measurement. Increasing the concentration of inhaled NO to $40 \mathrm{ppm}$ after the 15 min measurement did not result in a reduction of PAP (Table III) at the 30 min measurement and no differences in PAP, PVR or RV area were noted. 
TABLE II Gas Exchange data before and after bilateral cemented arthroplasty, for the control group ( $n=6$ ) and the NO group ( $n=6$ ) in which NO (40 ppm) was administered before BCA.

\begin{tabular}{|c|c|c|c|c|c|c|}
\hline & \multirow[t]{2}{*}{ Group } & \multirow{2}{*}{$\begin{array}{l}\text { Baseline } \\
\text { (post-ream) }\end{array}$} & \multicolumn{4}{|c|}{ After $B C A$} \\
\hline & & & $3 \min$ & $5 \min$ & $15 \min$ & $30 \mathrm{~min}$ \\
\hline \multirow{4}{*}{$\begin{array}{l}\mathrm{PaO}_{2} \\
\left(\mathrm{mmHg}^{2}\right) \\
\mathrm{PaO}_{2} / \mathrm{F}_{1} \mathrm{O}_{2}\end{array}$} & Control & $88 \pm 17$ & $60 \pm 17$ * & $60 \pm 15 *$ & $62 \pm 15$ * & $62 \pm 15 *$ \\
\hline & NO & $111 \pm 17$ & $77 \pm 18$ * & $77 \pm 20$ * & $76 \pm 19 *$ & $76 \pm 19 *$ \\
\hline & Control & $300 \pm 80$ & $217 \pm 62$ * & $216 \pm 53$ * & $222 \pm 57^{*}$ & $223 \pm 56$ * \\
\hline & NO & $409 \pm 62$ & $287 \pm 86$ * & $286 \pm 95 *$ & $281 \pm 92$ * & $283 \pm 95^{*}$ \\
\hline \multirow[t]{2}{*}{$\mathrm{F}_{\mathrm{I}} \mathrm{O}_{2}$} & Control & $.30 \pm .04$ & $.28 \pm .02$ & $.28 \pm .02$ & $.28 \pm .01$ & $.28 \pm .01$ \\
\hline & NO & $.27 \pm .03$ & $.27 \pm .03$ & $.28 \pm .03$ & $.28 \pm .03$ & $.28 \pm .03$ \\
\hline \multirow{4}{*}{$\begin{array}{l}\mathrm{PaCO}_{2} \\
\text { (mmHg) } \\
\text { Inhaled NO } \\
\text { Concentration } \\
\text { (ppm) }\end{array}$} & Control & $36 \pm 4$ & $39 \pm 3$ & $38 \pm 2$ & $38 \pm 2$ & $38 \pm 2$ \\
\hline & NO & $36 \pm 4$ & $40 \pm 5$ & $38 \pm 6$ & $39 \pm 5$ & $39 \pm 5$ \\
\hline & Control & 0 & 0 & 0 & 0 & 0 \\
\hline & NO & 40 & 40 & 40 & 40 & 40 \\
\hline
\end{tabular}

Values are mean \pm SD

* denotes a significant difference from post-reaming baseline $P<0.05$.

There were no significant differences between the control and NO group.

TABLE III Hemodynamic and Gas Exchange data. NO was administered after the one minute measurement and increased after the $15 \mathrm{~min}$ measurement $(\mathrm{n}=8)$.

\begin{tabular}{|c|c|c|c|c|c|c|c|c|}
\hline & $\begin{array}{l}\text { Baseline } \\
\text { (post-ream) }\end{array}$ & $1 \min$ & & $3 \min$ & $\begin{array}{c}A \text { fter } B C A \\
5 \mathrm{~min}\end{array}$ & $15 \mathrm{~min}$ & $E$ & $30 \mathrm{~min}$ \\
\hline$\overline{\mathrm{BP}}(\mathrm{mmHg})$ & $99 \pm 8$ & $80 \pm 20$ & 哀 & $91 \pm 16$ & $107 \pm 21$ & $92 \pm 15$ & $\frac{a}{a}$ & $84 \pm 13$ \\
\hline $\mathrm{PAP}(\mathrm{mmHg})$ & $16 \pm 4$ & $33 \pm 8^{*}$ & 尺్త & $30 \pm 7^{*}$ & $29 \pm 6^{*}$ & $25 \pm 4^{*}$ & q & $25 \pm 4^{*}$ \\
\hline PAOP (mmHg) & $8 \pm 2$ & $11 \pm 3$ & $\omega$ & $10 \pm 3$ & $9 \pm 1.3$ & $8 \pm 2$ & 범 & $8 \pm 2$ \\
\hline $\mathrm{RAP}(\mathrm{mmHg})$ & $6 \pm 1.4$ & $8 \pm 1.4$ & $E$ & $7 \pm 1.2$ & $7 \pm 1.1$ & $7 \pm 0.9$ & 䓅 & $6 \pm 1.7$ \\
\hline $\mathrm{Q}(\mathrm{l} / \mathrm{min})$ & $3.6 \pm 0.9$ & $3.1 \pm 1.0$ & 0 & $3.6 \pm 1.0$ & $3.9 \pm 1.3$ & $4.0 \pm 1.0$ & $\hat{0}$ & $4.1 \pm 1.0$ \\
\hline $\mathrm{PaO}_{2}(\mathrm{mmHg})$ & $155 \pm 31$ & $126 \pm 38^{*}$ & 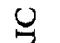 & $98 \pm 29^{*}$ & $83 \pm 27$ & $84 \pm 26$ & $\mathcal{U}$ & $71 \pm 24$ \\
\hline $\mathrm{PaCO}_{2}(\mathrm{mmHg})$ & $38 \pm 4$ & $41 \pm 4$ & $\underline{Z}$ & $41 \pm 4$ & $40 \pm 3$ & $40 \pm 4$ & 2 & $40 \pm 4$ \\
\hline RV area $(\mathrm{sq} \mathrm{cm})$ & $14.7 \pm 4.2$ & $21.3 \pm 3.2^{*}$ & $\bar{z}$ & $18.8 \pm 3.4^{*}$ & $17.3 \pm 3.3^{\star}$ & $14.9 \pm 3.6$ & $\bar{Z}$ & $14.1 \pm 3.5$ \\
\hline PVR (dyne-sec. $\mathrm{cm}^{-5}$ ) & $164 \pm 37$ & $625 \pm 252^{*}$ & & $459 \pm 177^{*}$ & $425 \pm 121^{*}$ & $340 \pm 73^{*}$ & & $321 \pm 67^{*}$ \\
\hline
\end{tabular}

Values are mean $\pm \mathrm{SD}$

* denotes a significant difference from post-reaming baseline $P<0.05$

The RV area increased immediately after BCA with a return to baseline value by $15 \mathrm{~min}$. The change (increase) in RV area when inhaled NO was given immediately after the increase in PAP (Part B) was no different at any time period from that in the control group (Part A). The RV area decreased from the dilated state at one minute after BCA to the five minute ($3.5 \pm 2.9 \mathrm{sq} \mathrm{cm}), 15 \mathrm{~min}(-5.6 \pm 3.4 \mathrm{sq} \mathrm{cm})$ and 30 $\min (-6.3 \pm 3.8 \mathrm{sq} \mathrm{cm})$ measurements.

With the addition of inhaled NO $20 \mathrm{ppm}$, there was a $31.8 \%$ decrease in PVR from the one minute measurement to the five minute measurement (-199 dyne $\left.\cdot \sec \cdot \mathrm{cm}^{-5}\right)$ and a $45.6 \%$ decrease in PVR at the 15 min measurement $\left(-285\right.$ dyne $\left.\cdot \mathrm{sec} \cdot \mathrm{cm}^{-5}\right)$ which persisted through the $30 \mathrm{~min}$ measurement $(-48.5 \%)$. However, at one minute the control group (Part A) had a similar PVR $\left(653 \pm 112\right.$ dyne $\left.\cdot \mathrm{sec} \cdot \mathrm{cm}^{-5}\right)$ and the decrease was $16.4 \%, 29.2 \%$ and $46.7 \%$ at 5,15 and 30 min measure- ments. When compared with the control group (Part A), there was no significant difference in the decrease in PVR from the one minute measurement.

Postmortem InTRAVAscular Fat: The mean diameter of lung vessel occluded by fat in each group at postmortem examination was $23.1 \pm 1.3 \mu \mathrm{m}$ in the control group, $25.9 \pm 4.4 \mu \mathrm{m}$ in the NO group and $22.5 \pm 4.4 \mu \mathrm{m}$ in Part B $(P>0.05)$. The number of emboli occluding vessels of specific diameters are shown in Figure 2. In all three groups the majority of vessels occluded at postmortem ( $30 \mathrm{~min}$ after BCA) were in the 10-20 $\mu \mathrm{m}$ range. There were no differences between the groups in the size distribution of vessels occluded $(P>0.05)$ (Figure 2$)$

\section{Discussion}

The major findings of this study are that, in this model, inhaled NO did not attenuate the acute pul- 
monary hypertension or RV dilation that accompanied fat and marrow embolism after BCA or alter the mean diameter of vessels occluded by fat emboli. This was independent of whether the inhaled NO was given before the embolic insult or after pulmonary hypertension was established.

Our hypothesis was that inhaled NO would reduce the RV afterload, and thus improve RV function. Right ventricular function was assessed with invasive monitoring as well as TEE which has been shown to provide useful added information in hypoxic states. ${ }^{12}$ The mechanism for improved RV function could be either reduced RV afterload or reduced hypoxemia, both resulting from selective pulmonary vasodilatation. Inhaled NO has been found to reduce PVR and improve gas exchange in some patients with acute lung injury. However, in these studies, the response to inhaled NO was inconsistent and variable and some patients were "non-responders". ${ }^{13}$ Manktelow and Rossaint reported that some patients with ARDS do not respond to inhaled NO and suggested that this may relate to varying causes of acute lung injury. ${ }^{9,14}$ In Part A of our study we found no improvement in hemodynamic values. Although $\mathrm{PaO}_{2}$ was higher in the NO group it was not different from control.

Although inhaled NO did not attenuate the immediate pulmonary hypertension, RV dilation or decreased SV, our data only reflect acute fat-induced, pulmonary hypertension and a later beneficial effect on gas exchange or the inflammatory response to acute lung injury beyond the $30 \mathrm{~min}$ study period is possible. The lack of hemodynamic response to inhaled NO in our study may be related to several factors. First, the large increase in PAP may be primarily caused by mechanical obstruction of the pulmonary vasculature. This would minimize any reversible pulmonary vasoconstriction caused by mediator release or hypoxic pulmonary vasoconstriction. Second, there may have been insufficient time for non-mechanical, vasoconstrictive factors to develop (e.g. endothelin release). Third, the site of pulmonary vasodilatation by inhaled NO may be different from the site of vasoconstriction during fat embolism. ${ }^{15} \mathrm{~A}$ fourth factor may be the canine model itself. However, in previous studies this animal model has accurately reproduced the human response to massive fat embolism ${ }^{7,8,17}$ and other studies have shown that inhaled NO attenuates pulmonary hypertension in some acute lung injury models in dogs. ${ }^{10,16}$ Hopkins et al. emphasize that the effects of NO in dogs is dependent on the low ventilation/perfusion zones present ${ }^{18}$ and in humans with ARDS, the response to inhaled NO varies and depends on the cause..$^{13,14}$
The pulmonary vessels occluded by fat at post mortem were primarily $10-20 \mu \mathrm{m}$ in diameter. These are smaller vessels than those that subtend the functional gas exchange unit in the lung. ${ }^{19}$ Young $e t$ al. used spherical polystyrene beads of specific size and showed that injection of 50 and $100 \mu \mathrm{m}$ beads never gave rise to high $\mathrm{V} / \mathrm{Q}$ regions, whereas larger diameter beads occluded functional gas exchange lung units. ${ }^{19}$ It is not surprising then, that fat emboli which occlude such small vessels $(<100 \mu \mathrm{m})$ do not create large areas of $\mathrm{V} / \mathrm{Q}$ mismatch. In this model, functional alveolar gas exchange was well maintained in spite of fat occlusion of a large number of small alveolar vessels (Figure 2).

Inhaled NO did not change the distribution of diameter of pulmonary vessels occluded by fat at post mortem (Figure 2). We have previously shown that intravascular fat moves through the pulmonary vasculature over the first three hours after BCA in this model. ${ }^{8}$ We hypothesised that the diameter of lung vessel occluded by fat would be smaller in animals given inhaled NO due to arteriolar vasodilatation, increasing the rate at which deformable fat emboli pass through the lung. Without data on the amount of fat reaching the systemic circulation, we cannot state with certainty that this did occur.

Contrary to our findings, Fahmy et al. recently reported that inhaled NO reversed small increases in PAP in eight patients during revision arthroplasty ${ }^{20}$ The difference between our data and Fahmy's clinical experience may relate to the smaller embolic load present in his patients than in our dogs. His elderly patients may have intrinsic lung disease which results in $\mathrm{V} / \mathrm{Q}$ mismatching under anesthesia, which is not present in our animals. In such circumstances, inhaled NO may cause vasodilatation that would decrease PAP. The effectiveness of inhaled NO after massive intra-operative fat embolism would be very difficult to study in patients as this degree of embolism (Ereth grade 7-9) occurs only rarely and active resuscitation is often required. ${ }^{1}$ An extremely large sample size would be needed to perform this clinical study. Most patients who have a small embolic load or good cardiopulmonary reserve do not need active intervention and recover spontaneously. More work needs to be done to identify high-risk groups who are specifically prone to cardiovascular collapse during cemented arthroplasty. Studies with bilateral procedures or simultaneous insertion of two long-stemmed prostheses (as in our model) suggest that cardiovascular collapse is related to a larger embolic load.

The mechanical obstruction of the pulmonary vasculature by fat decreases over time as the compressible fat emboli pass through the lung. ${ }^{8}$ The resolution of 
the mechanical obstruction over time is anticipated. However, there may be vasoconstriction and inflammatory changes later in the disease process that could be minimized by inhaled NO. The transpulmonary passage of fat accounts for the slow decrease in PAP over hours which has been noted in this model as well as patients. ${ }^{21}$

In conclusion, inhaled NO was ineffective in reducing the immediate hemodynamic changes during cemented arthroplasty in a clinically relevant dog model of massive fat embolism.

\section{Acknowledgments}

The authors wish to thank the Ontario Thoracic Society for financial support as well as Mr. Daniel Wigglesworth for technical assistance and Ms. Kerry McClenaghan for preparation of the manuscript.

\section{References}

1 Ereth $M H$, Weber JG, Abel MD, et al. Cemented versus noncemented total hip arthroplasty - embolism, hemodynamics, and intrapulmonary shunting. Mayo Clin Pro 1992; 67: 1066-74.

2 Fitzgerald R, Mason L, Kanumilli V, Kleinhomer K, Sakamoto A, Johnson C. Transient cardiac standstill associated with embolic phenomena diagnosed by introperative transesophageal echocardiography during cemented total hip arthroplasty. Anesth Analg 1994; 79: 382-5.

3 Pell ACH, Cbristie J, Keating JF, Sutherland GR. The detection of fat embolism by transoesophageal echocardiography during reamed intramedullary nailing. A study of 24 patients with femoral and tibial fractures. J Bone Joint Surg 1993; 75-B: 921-5.

4 Urban $M K$, Sheppard $R$, Gordon $M A$, Urquhart $B L$. Right ventricular function during revision total hip arthroplasty. Anesth Analg 1996; 82: 1225-9.

5 Propst JW, Siegel LC, Schnittger I, Foppiano L, Goodman SB, Brock-Utne JG. Segmental wall motion abnormalities in patients undergoing total hip replacement: correlations with intraoperative events. Anesth Analg 1993; 77: 743-9.

6 Pietak S, Holmes J, Matthews R, Petrasek A, Porter B. Cardiovascular collapse following femoral prosthesis surgery for acute hip fracture. Can J Anaesth 1997; 44: 198-201.

7 Murphy P, Edelist G, Byrick RJ, Kay JC, Mullen JB. Relationship of fat embolism to haemodynamic and echocardiographic changes during cemented arthroplasty. Can J Anaesth 1997; 44: 1293-300.

8 Byrick RJ, Mullen JB, Mazer CD, Guest CB. Transpulmonary systemic fat embolism. Studies in mongrel dogs after cemented arthroplasty. Am J Respir Crit Care Med 1994; 150: 1416-22.
9 Rossaint R, Falke KF, Lopez F, Slama K, Pison U, Zapol $W M$. Inhaled nitric oxide for the adult respiratory distress syndrome. N Engl J Med 1993; 328: 399-405.

10 Pison U, Lopez FA, Heidelmeyer CF, Rossaint R, Falke $K J$. Inhaled nitric oxide reverses hypoxic pulmonary vasoconstriction without impairing gas exchange. $\mathrm{J}$ Appl Physiol 1993; 74: 1287-92.

11 Stewart TE, Valenza F, Ribeiro SP, et al. Increased nitric oxide in exhaled gas as an early marker of lung inflammation in a model of sepsis. Am J Respir Crit Care Med 1995; 151: 713-8.

12 Vedrinne JM, Curtil A, Martinot $S$, et al. The hemodynamic effects of hypoxemia in anesthetized pigs: a comparison between right heart catheter and echocardiography. Anesth Analg 1998; 87: 21-6.

13 Treggiari-Venzi $M$, Ricou B, Romand J-A, Suter PM. The response to repeated nitric oxide inhalation is inconsistent in patients with acute respiratory distress syndrome. Anesthesiology 1998; 88: 634-41.

14 Manktelow C, Bigatello LM, Hess D, Hurford WE. Physiologic determinants of the response to inhaled nitric oxide in patients with acute respiratory distress syndrome. Anesthesiology 1997; 87: 297-307.

15 Galinier M, Rougé $P$, Fourcade J, et al. Lack of haemodynamic effects of nitric oxide on post-capillary pulmonary hypertension induced by acute sino-aortic denervation. Br J Pharmacol 1997; 120: 7-12.

16 Mélot C, Vermeulen F, Maggiorini M, Gilbert E, Naeije $R$. Site of pulmonary vasodilation by inhaled nitric oxide in microembolic lung injury. Am J Respir Crit Care Med 1997; 156: 75-85.

17 Orsini EC, Byrick RJ, Mullen JBM, Kay JC, Waddell JP. Cardiopulmonary function and pulmonary microemboli during arthroplasty using cemented or noncemented components. J Bone Joint Surg 1987; 69A: 822-32.

18 Hopkins SR, Jobnson EC, Richardson RS, Wagner $H, D e$ Rosa $M$, Wagner $P D$. Effects of inhaled nitric oxide on gas exchange in lungs with shunt or poorly ventilated areas. Am J Respir Crit Care Med 1997; 156: 484-91.

19 Young I, Mazzone RW, Wagner PD. Identification of functional lung unit in the dog by graded vascular embolization. J Appl Physiol 1980; 49: 132-41.

20 Fabmy NR, Head CA, Natban N, Zapol WM. Inhaled nitric oxide reverses acute pulmonary hypertension and hypoxemia during orthopedic procedures. Anesthesiology 1997; 87: Al120.

21 Byrick RJ, Forbes D, Waddell JP. A monitored cardiovascular collapse during cemented total knee replacement. Anesthesiology 1986; 65: 213-6. 